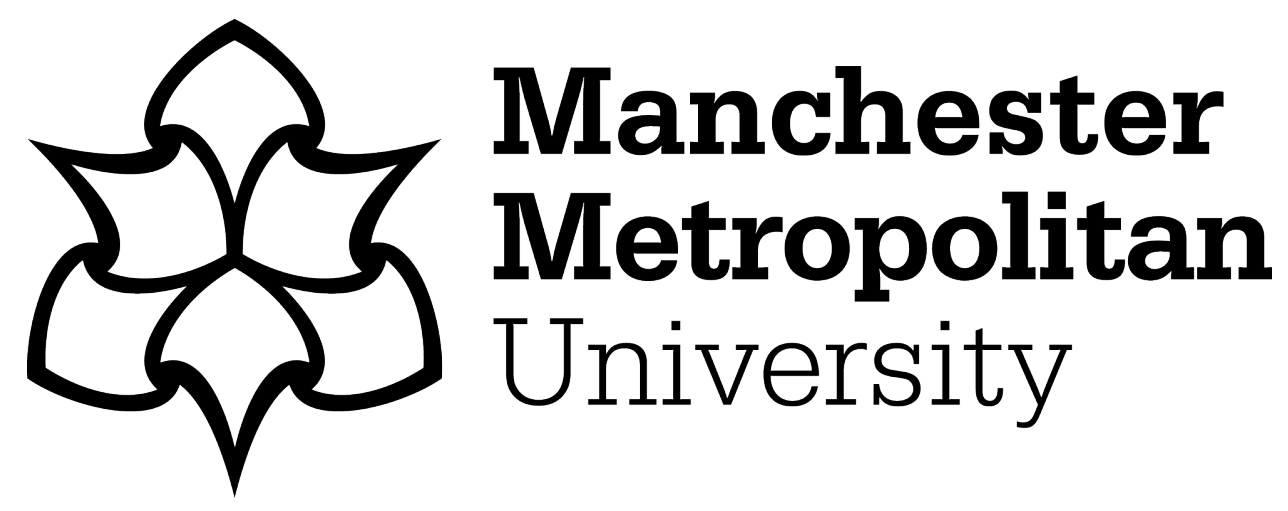

Wilson, S, King, M, Yeowell, G ORCID logoORCID: https://orcid.org/00000003-3872-9799 and Wibberley, C ORCID logoORCID: https://orcid.org/0000-0002-2037-6588 (2016) Disclosure decisions within transition narratives: how ex-drug users decide what information to share when working toward employment in the substance misuse field. Journal of Substance Use, 21 (6). pp. 575-580. ISSN 1465-9891

Downloaded from: https://e-space.mmu.ac.uk/604425/

Version: Accepted Version

Publisher: Taylor \& Francis

DOI: https://doi.org/10.3109/14659891.2015.1112849

Please cite the published version 
Disclosure Decisions within Transition Narratives: how ex-drug users decide what information to share when working towards employment in the substance misuse field.

(Disclosure decisions by ex-drug users)

\author{
Sheila Wilson ${ }^{\text {a }}$ Training Coordinator. BA, PG Dip, MSc, PhD \\ Martin King ${ }^{\mathrm{b}}$ Head of Social Care. Msc, PhD \\ Gill Yeowell ${ }^{\mathrm{b}}$ Senior Lecturer. PGCE, MSc, PhD \\ Christopher Wibberley ${ }^{\mathrm{b}}$ Principal Lecturer. BA, PGCE, MSc, PhD
}

\footnotetext{
${ }^{a}$ Greater Manchester West Mental Health NHS Foundation Trust, Chapman-Barker Unit, Prestwich Hospital, Bury New Road, Prestwich, Greater Manchester M25 3BL

${ }^{\mathrm{b}}$ Faculty of Health, Psychology \& Social Care, Manchester Metropolitan University, Brooks Building,53 Bonsall Street, Manchester, M15 6GX.
}

Corresponding author Dr Sheila Wilson

Address: Greater Manchester West Mental Health NHS Foundation Trust, Chapman-Barker Unit, Prestwich Hospital, Bury New Road, Prestwich, Greater Manchester M25 3BL

'phone: 01617723558

email: Sheila.wilson@gmw.nhs.uk 


\title{
Disclosure Decisions within Transition Narratives: how ex-drug users decide what information to share when working towards employment in the substance misuse field.
}

\begin{abstract}
:
Most ex-user narratives 'end' at the point where treatment ends, leaving much to discover regarding what happens next. Within this post-treatment experience, ex-users making the transition to work in the drugs field must decide whether or not to disclose their past substance use and, if they do disclose, further personal decision-making relates to how much to disclose, to whom, and in what context.
\end{abstract}

This article explores ex-drug users' decisions around disclose of their background to colleagues and service users. In-depth narrative interviews were undertaken with 11 ex-drug users to explore their journey to become substance misuse practitioners and their decisions around disclosure within this transition. Process-mapping was used to enable participants to structure their story in their own way.

Following analysis it became apparent that most participants received little or no guidance regarding disclose. In the absence of clear guidelines regarding personal disclosures, reflective practice could be seen as a potential tool to enable participants to assess such risks and rewards. Alongside personal reflexivity, consideration should be given by service providers to recruitment practices, disclosure policies, induction, training and supervision in order to support ex-user drug workers' disclosure decision-making.

Key words: disclosure, narrative, ex-user transition 


\section{Disclosure Decisions within Transition Narratives: how ex-drug users decide what information to share when working towards employment in the substance misuse field.}

\section{Introduction}

Most ex-substance user narratives already available 'end' at the point where treatment ends (for example: Addenbrooke 2011; Hurwitz, Tapping \& Vickers 2007; Jason, Olson \& Foli 2008; Sinisi 2009) leaving much to discover from ex-user narratives regarding what happens next. Without opportunities for ex-users to share their 'later' transition stories, key elements of their journeys may be omitted leaving others (including current service users and colleagues) in the dark about how ex-users achieve sustained recovery and/or paid employment. Ex-users may engage in a number of roles within the substance misuse field post-treatment, for example peer mentor, recovery champion and/or volunteer (each of which may involve an element of acting as a role model to current service users) prior to seeking paid work. It could be considered that in order for ex-users to act as role models, disclosure of their transition journey is necessary. Within such post-treatment experience, ex-users making the transition to work in the drugs field must not only decide whether or not to disclose their past substance use but, if they do disclose, they must make further personal decisions regarding how much to disclose, to whom and in what context.

Chaudoir and Fisher (2010) suggest "disclosure begins with a decision-making process in which disclosure goals affect the likelihood of disclosure in a given situation" (p240). Thus, an individual's motivation to disclose and their desired outcome from disclosure, influences not only the decision to disclose or not but also the "depth, breadth, duration, and emotional content" (Chaudoir \& Fisher 2010, p240) of any such disclosure. Furthermore, the "reaction of the confidant" (Chaudoir \& Fisher 2010, p240) will influence the likelihood and extent of 
any future disclosure. Chaudoir and Fisher (2010 p252) also described how disclosers can positively influence, to a lesser or greater degree, how individuals respond to their personal disclosure; suggesting that by teaching skills in communication and self-regulation disclosers might "improve the chances of eliciting positive, supportive responses from their confidants". This may be equally applicable to the training needs of ex-user drug workers so that they become skilled and confident in their method of disclosure within the substance misuse field.

This article reports on selected findings from a wider study that explored the narratives of those making the transition from ex-user to drug worker. The aim of the 'parent study' was to understand how non-qualified, ex-user drug workers make the transition from service user to paid employee in the substance misuse field, in order to facilitate greater understanding of their experiences in becoming and developing as drug practitioners. Disclosure emerged as a recurrent theme in the analysis of the participant narratives; and so it was decided to explore what they said about disclosure through a thematic analysis of the data in relation to this aspect of their overall experiences. Thus the aim of this paper is to explore ex-user drug workers' perceptions of disclosure decisions they made in their transition to becoming drug workers.

\section{Method}

\section{Data Collection}

Using purposive sampling, 11 ex-users who had completed a Level 3 Substance Misuse qualification were identified as willing to participate in narrative interviews to share their journey of becoming practitioners - Adam, Debbie, Elizabeth, Harry, Jamie, Kieran, Luke, Michael, Nicola, Phil, and Richard (not their real names). In-depth narrative interviews were used to explore the participants' transition to substance misuse worker (Lieblich et al. 1998). 
Participants were interviewed twice, the dialogue recorded and transcribed verbatim before analysis.

When collecting narrative accounts, it is conventional to use either unstructured interviews to offer opportunities for participants to tell their story in their own words (Mishler 1999) or an interview schedule that will recede "into the background" as participants "set their own narrative agendas" (Gubrium 1993, p14). Like Mishler (1999) and Gubrium (1993) the authors wanted the participants to set their own agenda so a process-mapping technique was used for each participant to structure their story in their own way. Process-mapping is an approach the participants were familiar with - either through using them with their own drug worker, or with their own clients, and has an evidence-base in drug services through many U.S. \& U.K. studies (Joe et al.1997; Carpenito-Moyet 2005).

Each participant was asked to undertake a 'process-mapping' exercise (an example has been provided in Figure 1) where participants chronologically 'plotted' their own story using postit notes, markers and flipchart paper, choosing topics they were comfortable discussing and that they felt best reflected their experience. The initial interview occurred alongside the 'process-mapping' exercise with a follow-up interview taking place at a mutually convenient time and place approximately 6-10 weeks afterwards to allow both the researcher and participant time to reflect on the process-maps (copies of their maps were sent to the participants straight after the first interview).

The participants decided themselves where to start their story; what information to include, for example, significant people, turning points, difficulties, opportunities, and so on. It was not expected that participants would be completely accurate in their recollection of dates but 
that they would attempt to get things in the 'right order'. This was facilitated by the visual mapping so that as they remembered things they could move post-it notes to make space for additional events.

\section{Figure 1. Example of a simplified process map - Jamie}

\section{Data Analysis}

The following step-by-step approach to the analysis was adopted:

Listening to taped recordings of the narrative interviews to hear the stories as a whole and get an overall impression of meaning and context

Transcribing the recordings, making notes of initial interpretations, tone, pauses, and so forth.

Listening to the tapes again in conjunction with reviewing the transcripts and process-maps, making further notes.

Writing a summary 'story' of each narrative to capture its 'whole' (Gubrium 1993; Riessman 1993) before doing detailed thematic analysis through the use of holistic-content reading (Lieblich et al. 1998).

Each participant's narrative was detailed using the table headings of 'narrative', 'initial impressions', 'interpretation' and 'initial theme' (Carlander et al. 2011; Lieblich et al. 1998). 
Initial themes from each participant's transcription were collated and reviewed to identify emergent key themes (Lieblich et al. 1998; Riessman 1993).

The above step-by-step process has been described as if it is linear when, in fact, it is iterative and hermeneutical in its approach (Gadamer 1975, 1976), with constant reflection on the findings from previous stages of analysis (Crist \& Tanner 2003). It is this reflexive process that facilitates a different understanding, for both researcher and participant, of the narratives co-constructed in this study (Gadamer 1975). As such, decisions regarding disclosure are likely to be affected by prior experience (positive and negative) of disclosure.

The participants were asked to share the story of their journey of becoming a drug worker so that their stories are told from the point at which they are now, i.e., as drug workers. This influences the lens through which they see their past lives as drug users (Gubrium 1993). In focusing on themes of disclosure, each participant's story was revisited and their 'disclosure story' was extracted from their text as a whole.

\section{Ethics}

Ethical approval was obtained from the Greater Manchester Central Research Ethics Committee (REC). To maintain ethical practice, consent forms were used and all identifying information anonymised through pseudonyms and the alteration of organisations, places, and so on.

\section{Results}

Disclosure - guidance and support 
Many participants discussed a lack of induction, training and supervision during their early days as volunteers or sessional workers - Adam, Debbie, Harry, Jamie, Elizabeth, Luke and Nicola all reported having little, if any, formal training, induction or supervision in their first volunteering role. This meant they had limited access to support to carry out their role, almost assuming that because they had been a substance user themselves, they would know automatically how to be a drug worker/volunteer. Only one participant, Luke, discussed having any guidance on disclosure during initial training and induction into his volunteering

role. He was advised not to disclose as part of a wider "don't ask, don't tell policy". He did not, however, let his volunteer coordinator know that he had breached the agency's boundaries; leaving him no back-up within the agency if he had needed any guidance or support as a result of disclosure. Other participants, for example, Michael and Harry, felt that disclosure was a personal decision rather than an agency one.

\section{Selective disclosure decisions}

Most of the 11 participants had disclosed in their first volunteering or paid roles (Adam, Debbie, Elizabeth, Luke, Nicola, Phil) and in some cases they were volunteering or working in the same agency where they were in treatment so that their status as an ex-user was already known (Harry, Jamie, Michael, Richard). The only participant who stated he had never disclosed his status in either volunteering roles or paid employment was Kieran.

While this early disclosure or 'being out' about one's past drug use was the norm amongst the participants, there was a great deal of variety regarding: whether they continued to disclose once they moved into subsequent posts or had gained qualifications; how much they disclosed to colleagues, clients or both; and how they decided if disclosure 'felt right'. Adam, Luke and Phil, for example, all stated that they chose not to disclose their past use to colleagues in their 
second paid posts; although they would on occasion disclose to individual clients if it felt 'appropriate'. They cited a range of reasons for the decision not to disclose:

Adam: “I didn't want anyone to find out I'm an ex-user cos they might judge me... I wanted to be able to first of all, go into the job and, you know, not say I've got this because I used to be a service user. You know, I wanted to go in and prove that I could do the job without formal qualifications and then earn respect from my colleagues and be a valued member of staff".

Luke: "I don't think it's anyone's business".

Phil: “I didn't disclose here [statutory service], but there was no [pause], they didn't ask about it. From memory, there was nothing on the application form."

The above experiences reflect disclosure theories (Chelune 1979; Collins \& Miller 1994; Derlega \& Grzelak 1979; Derlega et al. 1993) where participants selected to whom they were comfortable disclosing, having assessed their perception of risk for themselves and benefit for the client. The extent to which they disclosed - "nothing too prying" (Luke) - sets the "ceiling" of their disclosure and not going above this (Derlega \& Grzelak 1979, p163).

In reviewing the participants' disclosure narratives, it became apparent that some agencies had a 'norm' of disclosure whereas others did not. Some distinctions came from the 'status' of the service, for example, whether it was voluntary or statutory sector and how the participants felt about their role within each. Sometimes (in the case of Adam, for example) this was linked to the disclosure behaviours of others. Disclosure has been the norm in many alcohol and drug agencies, notably AA, and the advent of recovery Champions and the notion of visible recovery (Sinclair 2012) as inspiration has brought this issue to the fore again. 
Disclosure - risks, rewards and reciprocity

Richard was the only one in the sample who continued to work for the same agency where he was in treatment, having made the transition to paid drug worker through volunteering within the same setting. However, between his first and second interview, Richard was re-located to deliver his agency's groupwork programme in a new geographical location and within a multi-agency setting. This was the first time he had had to decide whether or not to disclose his past use:

“[I've not told my new colleagues] about my past. I've not said anything. It's just not come up, just not come up. I've told more of the clients. I'm more comfortable telling the clients than them [colleagues] for some reason."

For Richard, there was less perceived reward and more risks to disclosing to new colleagues in comparison with disclosing to clients where he had had prior positive experiences. For many years, Jamie was in a similar position to Richard as he volunteered and then worked for the same residential service where he himself was in treatment, meaning he was automatically 'out' about his ex-user status. Recently, however, he had worked in community-based services and stated:

\footnotetext{
“since I left the unit ... I've never divulged ... well, I have done if they've asked, I can’t remember ever saying, I don’t say, ‘my name’s Jamie and I'm an ex-user'. I never do it like that. They shouldn't ask, you know, but what's the point of telling lies?"
}

For both Jamie and Michael, there have been times when clients have guessed their background, for example, Michael said, “on occasion, they've come in and said, 'you're a user,' 'you're an ex-user'. And I'm like, 'who told you, then?' I won't deny it.” This reflects 
the interactional nature of disclosure decisions and relates to the disclosure theory of reciprocity (Chelune 1979): where clients disclose their backgrounds, Michael and Jamie felt 'obliged' to respond honestly when asked about their own experiences. Such decisions to disclose were being made while Jamie also acknowledged that clients may be pushing boundaries by asking about his past.

Chelune (1979, p249) has argued that "disclosure begets disclosure" in all interpersonal relationships and that this can be the case in drug agency work. However, any disclosure should, Collins and Miller (1994) argue, be appropriate in terms of breadth and depth - too little disclosure and others (including service users) may not trust the drug worker; too much, and professional boundaries are compromised.

While Michael was comfortable disclosing his past drug use on application forms and in conversation with colleagues and clients: "I think the service users appreciate the views of an ex-user worker", Debbie was less comfortable discussing her past with colleagues and only disclosed to clients if they challenged her about not understanding their situation:

"I don't trust them [ex-colleagues] as far as I could throw them. I mean I was quite an open person but I don't think like that anymore. I don't tell people me past, cos you get judged. And in the end, if new clients came I never disclosed. I only disclosed if they came in saying, 'you don't understand, you ain't got a clue' and that's when I'd say, 'yeah, I do.' Otherwise I kept my mouth shut.”

For Debbie, the perceived risk of disclosure is greater (especially with colleagues) than perceived benefits, even though there were occasions where she used her background to validate her role. Debbie was not the only one to have negative experiences relating to 
disclosure. Elizabeth had a negative response to disclosing her past in her first volunteering role within homelessness services, deciding from then on not to disclose to either clients or colleagues - again, the risks outweighed the potential benefits. Others, for example, Harry spoke positively of the response he got when disclosing his past use, saying,

"I've never found any negativity. Em, I tend to find people judge you on your knowledge base and maybe the way you present yourself... that's what I've found. It isn't a problem, em, I think it's been positive."

Clearly, such prior experiences of disclosure - positive or negative - strongly influenced future disclosure decision-making (Chelune 1979; Derlega \& Grzalek 1979). Even though Nicola did not experience any such difficulties as a volunteer she decided not to disclose her background once in paid employment, citing professional boundaries as the reason for this decision: "Well, you'd be breaking boundaries, aren't you, if you start talking about yourself and your past."

\section{Disclosure decisions - in transition}

Decisions relating to disclosure were also affected by how far the participants had come on their transition journey. For example, Adam stated,

'First thing I used to say was, 'I'm an ex-user, I'm an ex-service user.' And that was, kind of, em, cos that was all I had. I didn’t have any qualifications. That was ... I felt like [sighs], I felt like I had to justify what I did".

Adam, however, felt even at this early stage in his drug worker career that disclosure held some risks with which he was not comfortable: 
"And I remember, like, some of the [clients] used to say to you and it felt like they were trying to, not entrapment, but, like, manipulate, you know. Asking, 'what did you do?' Try and get a bit personal, asking about me personal... they were pushing the boundaries and asking, like, you know, what I used to do and what experience... it felt then like being on dodgy ground."

This meant that when Adam gained a new post in the statutory sector, he "felt like I didn't want to use this badge of 'I'm an ex-user'... I wanted to see if I could do it on me own”. Some ten years on, his views have become stronger and he asserts: "It seems a bit cringe-worthy to me, sometimes when people rely on this [ex-user] label" and Michael also implied that, in his opinion, there should be limits to the level of disclosure within the service setting by saying, "There is another chap here who discloses all the time, nah, bollocks to that." When applying for jobs, Michael disclosed his background, especially in early applications:

“I just say I'm in recovery myself. Em, yeah, that's something, I might not need to do that now. Is it a selling point? [pause] Yeah, it is. I'd probably do it [disclose]. Em, but it'd be very brief."

The perceived need to disclose appears to have reduced as the participants became more experienced as drug workers, and particularly after gaining qualifications. For example, Harry said,

"I don't want to wear the tag of ex-service user either really, you know, cos I'd like to think I'd have made a pretty good worker even if I hadn't been a service user."

\section{Discussion}

\section{Disclosure guidance}


The lack of disclosure guidance constitutes a significant gap in the induction programme for all substance misuse practitioners. Service providers seemed to assume ex-users (or, indeed, any other drug worker) automatically know what and how to disclose safely. What became apparent from the participants' experience of disclosure was that there was no obvious right or wrong answer to disclosure dilemmas. Some participants related tales of responding to personal questions as a 'knee-jerk' reaction or on the basis of 'gut instinct' without considering the implications of such disclosure. Without forethought any disclosure intervention remains unplanned, and without understanding underpinning theories and principles of disclosure the practitioners do not have access to an evidence-base. Almost all other interventions offered within drug treatment are part of a 'plan', for example, a care plan or recovery action plan. If we are to consider disclosure as an intervention (and the authors consider it to be so) then disclosure decisions need to be better planned and have a clear rationale for the disclosure or non-disclosure decision.

\section{Disclosure and identity}

Another factor to consider within the context of drug services is the link between disclosure and professional identity. What personal information volunteers or workers disclose influences how they see themselves and are seen by others, that is, their identity is formed and re-formed through their interaction with others. Through disclosure, including about past substance use, ex-users are interacting with their clients in narrative form, telling their substance use and/or recovery story. In doing so, they select which stories to tell; how much of the story to tell; and who to tell. Of the participants who did disclose, the stage of their transition journey influenced these factors; meaning they were more likely to disclose their past substance use earlier in their journey than later, for example, this was true for Adam and Phil. This suggests that at this stage, these volunteers and practitioners saw their identity 
more strongly in terms of ex-user than professional worker. As disclosure is more likely in the early stages when ex-users are closer to their own recovery experience (before ex-users have developed further experience and confidence), they are potentially more vulnerable to negative disclosure responses and consequences.

\section{Disclosure boundaries}

For some participants, there was no decision to make in their first volunteering or paid role because their identity as an ex-user was already known, for example, Jamie and Debbie. They could not 'take back' the information once it was 'out there' but they could decide how much detail to go into when discussing it with individuals or groups of clients. Michael made an interesting point in his narrative by distinguishing between 'disclosing' and 'identifying'. He made it clear that he was comfortable with 'identifying' himself as an ex-user with clients and colleagues but he did not feel the need to disclose any further details. The 'ceiling' for his disclosure was set. Others, like Elizabeth, Nicola and Kieran saw any personal disclosure as inappropriate and transgressing professional boundaries. The participants found their own balance by implementing boundaries to keep themselves safe while also utilising their personal experience as ex-substance users to act as a source of inspiration and hope.

\section{Disclosure and privacy}

There is a balance to be struck between disclosure and privacy. Disclosing too much information, too soon, in an inappropriate context, or to someone who does not want to hear that disclosure or who would misuse personal information, can carry negative consequences for the discloser and/or the recipient. Disclosing too little information, being defensive or failing to disclose when such an intervention would be appropriate can also carry risks and potentially undermine the developing professional relationship between worker and client. 
Disclosure does not always mean that a boundary has been crossed. Many participants had experience of managing disclosure balance decisions; of working out how much information was appropriate to disclose. For example, Richard learned to only disclose "snippets" as any further disclosure might cause the clients to "switch off". However, it is not just the needs of the clients that should influence whether or not disclosure is appropriate; it is also the needs of the volunteer or worker. Each individual has their own views of what they are and are not comfortable disclosing; their own perceptions of risks and benefits associated with disclosure.

It must also not be assumed that just because they have disclosed their status when interviewed for their post or to selected colleagues, that they are happy for all colleagues and clients to know their background or that they are obliged to go into details. As Luke put it, “You don't need to know which drugs I used, you don't need to know how I funded my habit, you don't need to know how I got drug free". It is the individual's information to share (or not), rather than the agency for whom they volunteer or work. Certainly, Luke concluded that, "it's up to me, isn't it, at the end of the day?"

\section{Decision-making principles}

Participants varied in their approaches to disclosure and identified a number of factors which impacted on their decisions. These included career stage, employer, relevance to clients and previous experiences of disclosure.

It has been suggested that self-disclosure is linked to individuals' desire to be liked by others (Collins \& Miller 1994). What this implies for the participants in this study is that they may be seen more favourably by their clients if they disclose their own past use, in comparison with either ex-users who choose not to disclose or non-ex-user drug workers. However, this 
does not suggest that disclosure (including for the participants in this study) is always appropriate, so being "selective about to whom to disclose" (Collins \& Miller 1994, p459) becomes the norm, as does how much to reveal and when. This was certainly true for Adam, Luke and Phil, for example, who all referred to their selective decision-making processes. According to Collins \& Miller 1994, disclosing too little information may cause suspicion (Jamie and Michael both expressed concerns about this); while disclosing too much may leave the worker vulnerable (Adam and Debbie shared such experiences), boundaries compromised (Nicola felt strongly about the importance of maintaining such boundaries while Phil had witnessed poor professional practice regarding boundaries in his first paid post), or the client overwhelmed (Richard had observed another colleague whose level of selfdisclosure had a negative impact on clients' involvement in group work). The participants (for example, Elizabeth) talked of disclosure decision-making as "risky" (Collins \& Miller 1994, p466), suggesting that, when deciding whether or not to disclose, or how much to disclose, individuals assess the potential rewards and risks of sharing before any disclosure, as “once we disclose, we can't take it back" (Collins \& Miller 1994, p471). Within the context of both personal and professional relationships, many individuals in this study set boundaries regarding their breadth and depth of disclosure, depending on the nature of their relationships (Derlega \& Grzelak 1979).

While self-disclosure can be beneficial for both teller and recipient (Derlega et al. 1993), it is also possible that individuals "use self-disclosure for social control, selectively presenting information about ourselves to create a good impression" (Derlega et al. 1993, p3). Certainly, this was referred to by some participants in terms of breaking down barriers and letting clients know they understood the clients' situations through having similar experiences. Therefore, 
the relationship can be seen as "mutually transformative" (Derlega et al. 1993, p6), so the worker gains from the interaction as well as the client.

The conclusion reached for most of the participants in this study appears to be that "[a]lthough self-disclosure about sensitive topics may pose risks, sharing this information with an appropriate disclosure recipient can be beneficial" (Derlega et al. 1993, p87). But, how do ex-user drug workers make such decisions and what support is available to facilitate confidence in such disclosures within the context of the substance misuse field? Omarzu's (2000, p197) ideas on "subjective utility versus subjective risk" as part of the decision making process is useful here. Risk assessment around disclosure on the part of the ex-user is based on a cost-benefit analysis, something which could be explored in drug worker induction training.

\section{Reflective practice}

Although not specifically reported in this way by the participants, such decision-making about disclosure appears to involve a degree of reflective practice, or as Derlega and Grzelak (1979) term it, "critical self-evaluation" (p. 157), whereby each person reflected on their past experience as a substance user and what responses they got from previous disclosure (Chelune 1979). This determines their present and future decisions about what and how much to communicate to others, for example, Elizabeth with her negative experience of selfdisclosure, reduced any sharing of information regarding her past substance use, whereas, Harry, with his positive responses to disclosing his past use, maintained a high level of disclosure to both clients and colleagues. How they therefore view themselves as an ex-user drug worker, or feel they are perceived by others, is strongly influenced by such disclosure experiences and reflective practices. 


\section{Conclusions and recommendations}

There is a lack of opportunities for ex-users to tell their transition narrative alongside their recovery narrative. Many participants were well-versed in their story of substance use and treatment but, for some, this was the first time they had narrated their later transition experiences. The participants had, however, made a range of disclosure decisions in their working lives in terms of how much they disclosed and in what context. While there is not necessarily a 'right or wrong' to disclosure, it is apparent that this personal decision-making lacks guidance and support within the context of substance misuse services. This gap potentially leaves ex-users vulnerable if they do not find an appropriate level of disclosure to suit themselves, their clients and the service where they work/volunteer. The following recommendations aim to balance the importance of narrative disclosure in enabling ex-users to act as role models with the need to assist ex-users in selective disclosure decision-making so as to safeguard their own and their clients' wellbeing:

- Ex-substance users need to be offered more opportunities and support to tell their 'later' transition stories, not just their recovery narratives as this will enable them to act as role models and inform other ex-users about later-stage transition processes.

- There should be no 'set' rules regarding whether or not an individual discloses their past substance use with disclosure being considered as a complex decision-making process not a simple 'yes' or 'no' decision. Instead, guidance and training should be offered regarding disclosure for all staff and volunteers from their earliest contact (induction) with the service, for example, how to get the most out of disclosure, managing responses to disclosures, selective disclosure, how to set a disclosure 'ceiling', reflecting on disclosure decisions, disclosure goals, pros and cons, 
risks and benefits, professional and personal boundaries, confidentiality and privacy.

- Disclosure should be considered to be an intervention in its own right with a clear evidence-base, goals and rationale for utilising this intervention. This will enable drug workers to optimise the effectiveness of disclosure decisions.

- Disclosure should be explored as part of a wider discussion regarding professional and personal boundaries to keep both service users and volunteers/workers safe.

The authors set out to identify areas for practice improvements and feel the above recommendations, if adopted, will facilitate this, not only for local practice but for a range of service providers. We also hope ex-user drug workers and potential ex-user drug workers will read and reflect on this study to influence their own ambitions, transition journeys, disclosure decisions and professional development.

The authors feel this study to be especially pertinent at this time as many substance misuse services are currently recruiting 'Recovery Champions' from within the ex-user population, welcoming applications exclusively from ex-users, the result of which is 'disclosure by default' as all colleagues and clients will know they are ex-users from the definition of their role. While 'Recovery Champions' are a welcome addition to the employment opportunities for ex-users, there may be implications for their confidentiality, identity and professional relationships that have yet to be considered. 
Acknowledgements: The authors would like to thank the participants for their input to this research by sharing their experiences.

\section{References}

Addenbrooke M. (2011). Survivors of Addiction. London: Routledge.

Carlander I., Ternestedt BM., Sahlberg-Blom E., Hellstrom I., \& Sandberg J. (2011). Four aspects of self-image close to death at home. Int J Qual Stud Health Well-being, 6(2), 59315945.

Carpenito-Moyet LJ. (2005). Nursing process and concept mapping. London: Williams \& Wilkins.

Chaudoir SR., \& Fisher JD. (2010). The disclosure processes model: Understanding disclosure decision-making and post-disclosure outcomes among people living with a concealable stigmatized identity. Psychological Bulletin, 138(2), 236-256.

Chelune GJ. (1979). Self-disclosure: origins, patterns, and implications of openness in interpersonal relationships. San Francisco: Jossey-Bass.

Collins NL. \& Miller LC. (1994). Self-disclosure and liking: a meta-analytic review. Psychological Bulletin, 116(3), 457-475. 
Crist JD., \& Tanner A. (2003). Interpretation/analysis in hermeneutic interpretive phenomenology. Nursing Research, 53(3), 202-205.

Derlega VJ., \& Grzelak J. (1979). Appropriateness of Self-Disclosure. In Chelune GJ. (Ed.), Self-disclosure: Origins, patterns, and implications of openness in interpersonal relationships. San Francisco: Jossey-Bass.

Derlega VJ., Metts S., Petronio S., \& Margulis ST. (1993). Self-disclosure. Newbury Park: Sage Publications.

Gadamer HG. (1975). Truth and method (2nd ed.). London: Continuum.

Gadamer HG. (1976). Philosophical hermeneutics. Berkeley: University \& California Press. Gubrium JF. (1993). Speaking of life: Horizons of meaning for nursing home residents. New York: Aldine De Gruyter.

Hurwitz B., Tapping C., \& Vickers N. (2007). Life Histories and Narratives of Addiction. In Nutt DJ., Robbins TW., Stimson GV., Ince M. \& Jackson A. (Eds.), Drugs and the future: British science, addiction and society. Burlington: Academic Press. Jason LA., Olsen BD., \& Foli K. (2008). Rescued lives: The Oxford House approach to substance abuse. New York: Routledge.

Joe GW., Dansereau DF., Pitre U., \& Simpson D. (1997). Effectiveness of node-link mapping enhanced counseling for opiate addicts: A 12-month posttreatment follow-up. The Journal of Nervous and Mental Disease, 185(5).

Lieblich A., Tuval-Mashiach R., \& Zilber T. (1988). Narrative research: Reading, analysis and interpretation. London: Sage Publications.

Mishler EG. (1999). Storylines: Craftartists' narratives of identity. Cambridge: Harvard University Press.

Omarzu J. (2000). A disclosure decision model: Determining how and when individuals will self-disclose. Personality and Social Psychology Review, 4(2), 174-185. 
Riessman CK. (1993). Narrative analysis. London: Sage Publications.

Sinisi V. (2009). Understanding addiction: Exploring the implications of users accounts of addiction. Saarbrucken: VDM Verlag. 